\title{
An outbreak of Aspergillus meningitis following spinal anaesthesia for caesarean section in Sri Lanka: a post-tsunami effect?
}

\author{
PS Gunaratne ${ }^{1}$, CN Wijeyaratne ${ }^{2}$, P Chandrasiri $^{3}$, S Sivakumaran $^{4}$, K Sellahewa $^{5}$, P Perera $^{6}$, R Fernando $^{7}$, \\ $\mathrm{J}$ Wanigasinghe ${ }^{8}$, S Jayasinghe ${ }^{9}$, R Ranawala ${ }^{10}$, MTM Riffsy ${ }^{11}$ and HR Seneviratne ${ }^{12}$
}

(Index words: latrogenic, Aspergillus meningitis, spinal anaesthesia, tsunami)

\begin{abstract}
An outbreak of Aspergillus fumigatus meningitis occurred in 5 women following spinal anaesthesia, performed between 21 June and 17 July 2005 for caesarean section, in Colombo, Sri Lanka. The patients' median age was 27 years. Different teams in 2 maternity hospitals gave spinal anaesthesia. Mean incubation period was 11.2 days. Fever, headache and nuchal rigidity were common presentations. Remittent fever continued despite broad-spectrum intravenous antibiotics. Papilloedema, lateral rectus palsy, cerebral infarction and haemorrhage developed later. Three patients died. Cerebrospinal fluid pleocytosis with low glucose yielded negative PCR for fungi. Fungal cultures subsequently grew Aspergillus fumigatus. A post-mortem of the first patient confirmed Aspergillus meningitis, followed by treatment with amphotericin B and voriconazole, that saved the lives of others. Visual and hearing impairment in one and complete recovery in the other were observed a year after treatment.
\end{abstract}

Examination of unused plastic syringes, needles, cannulae, and ampoules of anaesthetic agents confirmed that 43 syringes from three different manufactures were contaminated with Aspergillus fumigatus. The stores for drugs and devices of the Ministry of Health were examined and found to be full of tsunami donations, while regular procurements of the Ministry were kept in a poorly maintained humid warehouse. Inadequate space for tsunami donations was identified as the most plausible explanation for sub-optimal storage. Withdrawal and incineration of all unused syringes controlled the outbreak.

The survival of those aggressively treated for Aspergillus meningitis suggests in hindsight that the availability of diagnostic tests and specific treatment, and early recognition of the outbreak could have saved the lives of victims who died. Early life-threatening sideeffects and permanent long term sequelae of antifungal medication stress the need to be cautious with empirical treatment in immuno-competent low-risk individuals.

\section{Introduction}

Meningitis following lumbar puncture is extremely rare. A recent Medline review of meningitis following spinal anaesthesia found no reports caused by fungi [1]. However, a review of cases over two decades in India reported isolated cases of Aspergillus meningitis following spinal anaesthesia [2]. An outbreak of iatrogenic meningitis has not been reported previously. We report an outbreak of iatrogenic meningitis caused by Aspergillus fumigatus that occurred between 3 July to 25 July 2005 in Colombo, Sri Lanka. Clinical features, diagnostic issues, complications and outcomes in the management of these patients are described. The results of epidemiological investigations and measures taken to control the outbreak are also discussed.

\section{Emergence of the outbreak}

Five women presented to the National Hospital of Sri Lanka (NHSL) with features of meningitis following spinal anaesthesia performed for caesarean section in June/ July 2005. Four had delivered at De Soysa Hospital for Women (DSHW) and one (patient 5) at Castle Street Hospital for Women (CSHW).

Patient 1 who delivered uneventfully by caesarean section at DSHW and was discharged 4 days later, developed hemiparesis after 14 days and was transferred to Neurology Unit of NHSL from the local hospital. Patients 2, 3 and 4 were re-admitted to DSHW within 2 weeks from the date of admission of patient 1 . They had fever and headache and were managed as bacterial meningitis. They were referred subsequently to NHSL for specialized care.

Identification of the first 4 patients from DSHW during July 2005, prompted regular discussions among physicians, obstetricians, anaesthetists, microbiologists, medical administrators, epidemiologists and Maternal and Child Health Divisions of the Ministry of Health. Issues regarding case definition, microbiological diagnosis, optimal clinical management, screening all who had

\footnotetext{
${ }^{1.11}$ Neurologist, ${ }^{2}$ Physician in Reproductive Medicine, ${ }^{3}$ Microbiologist, ${ }^{4,5}$ General Physician, ${ }^{6}$ Mycologist, ${ }^{7}$ Pathologist, ${ }^{8}$ Senior Registrar in Neurology, ${ }^{9.10}$ Anaesthetist, ${ }^{12}$ Obstetrician and Gynaecologist. 1. 3. 4. 5. 7. 0. 10. 1"National Hospital of Sri Lanka, ${ }^{6}$ Medical Research Institute, Colombo, ${ }^{8}$ Faculty of Medicine, University of Colombo, and ${ }^{2,12}$ Professors, Faculty of Medicine, University of Colombo.

Correspondence: PSG, e-mail: <pagunara@hotmail.com> Competing interests: none declared. Received 15 Februany and accepted 18 February 2007.
} 


\title{
An outbreak of Aspergillus meningitis following spinal anaesthesia for caesarean section in Sri Lanka: a post-tsunami effect?
}

\author{
PS Gunaratne ${ }^{1}$, CN Wijeyaratne ${ }^{2}$, P Chandrasiri $^{3}$, S Sivakumaran $^{4}$, K Sellahewa $^{5}$, P Perera $^{6}$, R Fernando $^{7}$, \\ $\mathrm{J}$ Wanigasinghe ${ }^{8}$, S Jayasinghe ${ }^{9}$, R Ranawala ${ }^{10}$, MTM Riffsy ${ }^{11}$ and HR Seneviratne ${ }^{12}$
}

(Index words: latrogenic, Aspergillus meningitis, spinal anaesthesia, tsunami)

\begin{abstract}
An outbreak of Aspergillus fumigatus meningitis occurred in 5 women following spinal anaesthesia, performed between 21 June and 17 July 2005 for caesarean section, in Colombo, Sri Lanka. The patients' median age was 27 years. Different teams in 2 maternity hospitals gave spinal anaesthesia. Mean incubation period was 11.2 days. Fever, headache and nuchal rigidity were common presentations. Remittent fever continued despite broad-spectrum intravenous antibiotics. Papilloedema, lateral rectus palsy, cerebral infarction and haemorrhage developed later. Three patients died. Cerebrospinal fluid pleocytosis with low glucose yielded negative PCR for fungi. Fungal cultures subsequently grew Aspergillus fumigatus. A post-mortem of the first patient confirmed Aspergillus meningitis, followed by treatment with amphotericin B and voriconazole, that saved the lives of others. Visual and hearing impairment in one and complete recovery in the other were observed a year after treatment.
\end{abstract}

Examination of unused plastic syringes, needles, cannulae, and ampoules of anaesthetic agents confirmed that 43 syringes from three different manufactures were contaminated with Aspergillus fumigatus. The stores for drugs and devices of the Ministry of Health were examined and found to be full of tsunami donations, while regular procurements of the Ministry were kept in a poorly maintained humid warehouse. Inadequate space for tsunami donations was identified as the most plausible explanation for sub-optimal storage. Withdrawal and incineration of all unused syringes controlled the outbreak.

The survival of those aggressively treated for Aspergillus meningitis suggests in hindsight that the availability of diagnostic tests and specific treatment, and early recognition of the outbreak could have saved the lives of victims who died. Early life-threatening sideeffects and permanent long term sequelae of antifungal medication stress the need to be cautious with empirical treatment in immuno-competent low-risk individuals.

\section{Introduction}

Meningitis following lumbar puncture is extremely rare. A recent Medline review of meningitis following spinal anaesthesia found no reports caused by fungi [1]. However, a review of cases over two decades in India reported isolated cases of Aspergillus meningitis following spinal anaesthesia [2]. An outbreak of iatrogenic meningitis has not been reported previously. We report an outbreak of iatrogenic meningitis caused by Aspergillus fumigatus that occurred between 3 July to 25 July 2005 in Colombo, Sri Lanka. Clinical features, diagnostic issues, complications and outcomes in the management of these patients are described. The results of epidemiological investigations and measures taken to control the outbreak are also discussed.

\section{Emergence of the outbreak}

Five women presented to the National Hospital of Sri Lanka (NHSL) with features of meningitis following spinal anaesthesia performed for caesarean section in June/ July 2005. Four had delivered at De Soysa Hospital for Women (DSHW) and one (patient 5) at Castle Street Hospital for Women (CSHW).

Patient 1 who delivered uneventfully by caesarean section at DSHW and was discharged 4 days later, developed hemiparesis after 14 days and was transferred to Neurology Unit of NHSL from the local hospital. Patients 2, 3 and 4 were re-admitted to DSHW within 2 weeks from the date of admission of patient 1 . They had fever and headache and were managed as bacterial meningitis. They were referred subsequently to NHSL for specialized care.

Identification of the first 4 patients from DSHW during July 2005, prompted regular discussions among physicians, obstetricians, anaesthetists, microbiologists, medical administrators, epidemiologists and Maternal and Child Health Divisions of the Ministry of Health. Issues regarding case definition, microbiological diagnosis, optimal clinical management, screening all who had

\footnotetext{
${ }^{1.11}$ Neurologist, ${ }^{2}$ Physician in Reproductive Medicine, ${ }^{3}$ Microbiologist, ${ }^{4,5}$ General Physician, ${ }^{6}$ Mycologist, ${ }^{7}$ Pathologist, ${ }^{8}$ Senior Registrar in Neurology, ${ }^{9.10}$ Anaesthetist, ${ }^{12}$ Obstetrician and Gynaecologist. 1. 3. 4. 5. 7. 0. 10. 1"National Hospital of Sri Lanka, ${ }^{6}$ Medical Research Institute, Colombo, ${ }^{8}$ Faculty of Medicine, University of Colombo, and ${ }^{2,12}$ Professors, Faculty of Medicine, University of Colombo.

Correspondence: PSG, e-mail: <pagunara@hotmail.com> Competing interests: none declared. Received 15 Februany and accepted 18 February 2007.
} 
received spinal anaesthesia during June and July 2005, and prevention of any further cases, received particular attention. Patient 5 detected from CSHW during the third week of the illness of the first 4 patients suggested that an outbreak confined to DSHW was unlikely. Hence the scope of investigation and preventive action was widened.

Records of patients' operative delivery, subsequent clinical course, results of blood and cerebrospinal fluid analysis, and changes found in serial brain imaging were reviewed. A concurrent epidemiological investigation was done, adhering to international recommendations, for a suspected outbreak, by the Epidemiology Division of the Ministry of Health, Sri Lanka.

\section{Clinical setting}

Five healthy women underwent caesarean delivery under spinal anaesthesia. Their age distribution was 2138 years (median 27) (Table 1). The incubation period from the date of spinal anaesthesia for the development of clinical features ranged from 8-16 days (mean 11.2 days). Remittent fever exceeding $38^{\circ} \mathrm{C}$, excruciating headache, vomiting, neck pain, backache and photophobia were initial symptoms in all, except patient 5 who was afebrile. Neck stiffness and Kernig's sign at presentation were positive in all except patient 1 who manifested these on the 14th day. Persistent headache with swinging temperature despite multiple parenteral antibiotics was the striking feature in patients 1-4.

Neutrophil leucocytosis and a cellular reaction of the initial CSF aspirates were present in all (Table1). Only one had CSF study performed before giving antibiotics (patient 5 ), which revealed only lymphocytes $(235 / \mu \mathrm{l})$. Subsequent serial CSF studies had cell counts of 2000 to $7000 / \mu 1$ with development of neutrophil predominance over time. Low CSF glucose was a constant feature. CSF cultures of patient 5 grew Bacillus spp. CSF culture for fungi were negative and $\mathrm{PCR}$ performed on the three who deteriorated (patients of 1,2, and 5) was also negative.

Five underwent brain imaging with patient 1 showing a thalamic infarct. Repeat scans of patients 2 and 5 who had sudden neurological deterioration on days 28 and 14 , showed respectively thalamic infarct and intraventricular haemorrhage.

All were treated with large doses of intravenous antibiotics to cover possible gram-negative and grampositive organisms causing meningitis, without success. Upon suspicion of a possible fungal infection, the only available antifungal medication (fluconazole) in Sri Lanka was added empirically. Patient 1 had one week of intravenous fluconazole but died. Patients 2 and 5 received airlifted parenteral amphotericin $B$ for 3-5 days, but died.

Among survivors, patients 3 and 4 had a stormy clinical course, and were administered intrathecal and intravenous amphotericin B over the next 2-4 weeks. Patient 3 received voriconazole for 33 days. She developed impaired vision, deafness, thrombophlebitis and lumbar radiculopathy as complications. A threat to her vision led to stop voriconazole in the 5 th week. Patient 4 developed transient renal impairment for amphotericin B, and angioedema, bronchoconstriction and pruritic rash following parenteral voriconazole, but tolerated 12 weeks of oral voriconazole. She had persistent papilloedema and developed hydrochephalus that required ventriculoperitoneal shunting that was removed because of shunt infection later. Hypokalemia caused by amphotericin B required frequent intravenous potassium chloride replacement for both patients. Anaemia and agranulocytosis required erythropoietin and granulocyte colony stimulating factor treatment for both. They required intensive care for an average of 2 months.

Patients 1, 2 and 5 died on the 40th, 46th and 19th day of illness after sudden clinical deterioration, with hemiplegia, unconsciousness, and brainstem dysfunction despite optimal resuscitation in ICU.

Post-mortem examination of the first patient confirmed Aspergillus meningitis (Figures 1,2,3 and Table 2), which led to immediate treatment with amphotericin $B$ and voriconazole that saved the remaining two [3]. Patients 3 and 4 were in hospital for 135 and 153 days. Residual diplopia, deafness, visual impairment and proximal limb weakness in patient 3 and persistent papilloedema in patient 4 were observed upon discharge from hospital. Both remained afebrile and had normal intellectual and cognitive functions. A year later, patient 3 remains visually impaired with unilateral impaired hearing. Patient 4 recovered completely.

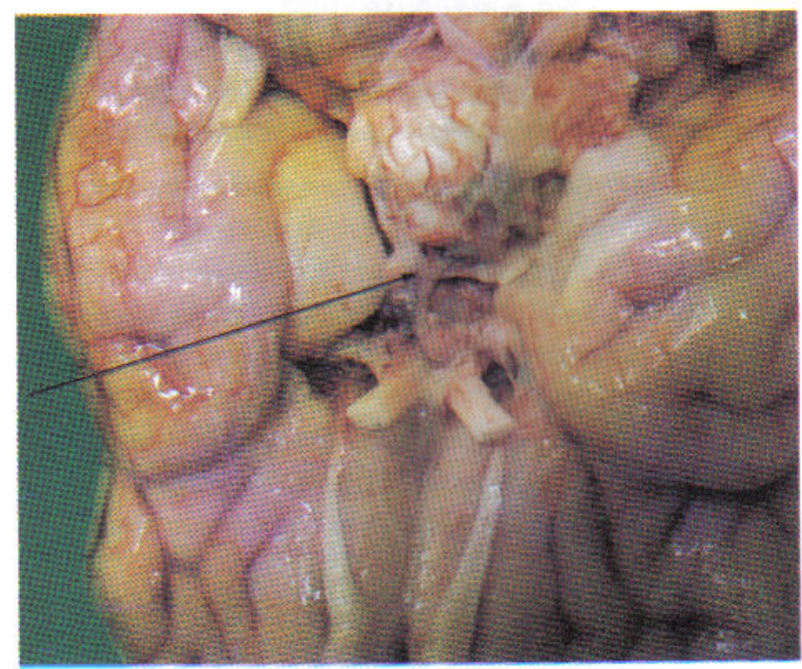

Figure 1. Macroscopy of brain (patient 1) showing meningeal exudates (arrow) around the Circle of Willis. 
Table 1. Clinical features, laboratory results, treatment modality, complications and outcome of the case series affected by iatrogenic meningitis

\begin{tabular}{|c|c|c|c|c|c|}
\hline Patients & $I$ & 2 & 3 & 4 & 5 \\
\hline \multicolumn{6}{|l|}{ Clinical features } \\
\hline Age (years) & 26 & 21 & 27 & 29 & 38 \\
\hline Date of exposure & June 21 & June 22 & June 20 & June 22 & July 17 \\
\hline $\begin{array}{l}\text { Date of onset of } \\
\text { symptoms }\end{array}$ & July 3 & July 2 & July 5 & July 3 & July 25 \\
\hline $\begin{array}{l}\text { Neck stiffness and } \\
\text { Kernig's sign }\end{array}$ & - & +++ & ++ & + & + \\
\hline Lateral rectus palsy & - & - & Bilateral & Bilateral & - \\
\hline Stroke & $\begin{array}{l}\text { Thalamic } \\
\text { infarction } \\
(09.07 .2005)\end{array}$ & $\begin{array}{l}\text { Thalamic } \\
\text { infarction } \\
(31.07 .2005)\end{array}$ & - & ' & $\begin{array}{l}\text { Ventricular } \\
\text { hemorrhage } \\
(10.08 .2005)\end{array}$ \\
\hline Complications & $\begin{array}{l}\text { Partial seizures, } \\
\text { diabetes insipidus }\end{array}$ & Partial seizures & $\begin{array}{l}\text { Deep vein } \\
\text { thrombosis }\end{array}$ & $\begin{array}{l}\text { Papilloedema, } \\
\text { hydrocephalus }\end{array}$ & $\begin{array}{l}\text { Coagulopathy } \\
\text { Polyuria }\end{array}$ \\
\hline \multicolumn{6}{|c|}{ Laboratory results - cerebrospinal fluid } \\
\hline Protein mg/dl & 68 & 49 & 134 & 33 & 28 \\
\hline $\begin{array}{l}\text { Glucose mg/dl } \\
\text { (RBG mg/dl) }\end{array}$ & $\begin{array}{l}56 \\
(115)\end{array}$ & $\begin{array}{l}25 \\
(90)\end{array}$ & $\begin{array}{l}21 \\
(133)\end{array}$ & $\begin{array}{l}45 \\
(120)\end{array}$ & $\begin{array}{l}61 \\
(109)\end{array}$ \\
\hline Neutrophil/ $\mu \mathrm{l}$ & 300 & 400 & 20 & 572 & Nil \\
\hline Lymphocytes $/ \mu$ l & 2 & 175 & 700 & 858 & 225 \\
\hline Gram stain & Negative & Negative & & Negative & Negative \\
\hline Cytology & Negative & Negative & Fungal spores + & Negative & Negative \\
\hline Amphotericin B & & $\begin{array}{l}\text { IV } \\
\text { (Aug 3 - death) }\end{array}$ & $\begin{array}{l}\text { IV } \\
\text { (Aug } 3 \text { - Sept 2) } \\
\text { IT - } 8 \text { doses } \\
\text { (2 / week) }\end{array}$ & $\begin{array}{l}\text { IV } \\
\text { (Aug } 5 \text { - Aug20) } \\
\text { IT - } 30 \text { doses } \\
\text { (2-3/ week) }\end{array}$ & $\begin{array}{l}\text { IV } \\
\text { (Aug } 10 \text { - Death) }\end{array}$ \\
\hline Voriconazole & & $\begin{array}{l}\text { IV } \\
\text { (Aug 13 - Aug 27) } \\
\text { Oral } \\
\text { (Aug 28 - Sept 15) }\end{array}$ & $\begin{array}{l}\text { IV } \\
\text { (Aug } 28-\text { Sept 4) } \\
\text { Oral } \\
\text { (Sept } 5 \text { - Dec 5) }\end{array}$ & & \\
\hline $\begin{array}{l}\text { Complications of } \\
\text { reatment }\end{array}$ & & $\begin{array}{l}\text { Impairment of } \\
\text { vision and hearing. } \\
\text { Bone marrow } \\
\text { suppression. } \\
\text { Proximal } \\
\text { weakness. }\end{array}$ & $\begin{array}{l}\text { Bone marrow } \\
\text { suppression. } \\
\text { Transient renal } \\
\text { impairment. } \\
\text { Hypersensitivity } \\
\text { to IV voriconazole. }\end{array}$ & & \\
\hline Dutcome & $\begin{array}{l}\text { Died } \\
\text { (Aug 2) }\end{array}$ & $\begin{array}{l}\text { Died } \\
\text { (Aug 7) }\end{array}$ & $\begin{array}{l}\text { Survived } \\
\text { ICU - } 60 \text { days. } \\
\text { Impaired } \\
\text { vision and } \\
\text { hearing at } 1 \text { year. }\end{array}$ & $\begin{array}{l}\text { Survived } \\
\text { ICU - } 62 \text { days. } \\
\text { No residual } \\
\text { disability. }\end{array}$ & $\begin{array}{l}\text { Died } \\
\text { (Aug 19) }\end{array}$ \\
\hline
\end{tabular}

CSF = cerebrospinal fluid; RBG = random blood glucose; IV = intravenous; IT = intrathecal;

$\mathrm{DVT}=$ deep vein thrombosis; ICU = intensive care unit, ${ }^{*}=$ diagnosis not confirmed 


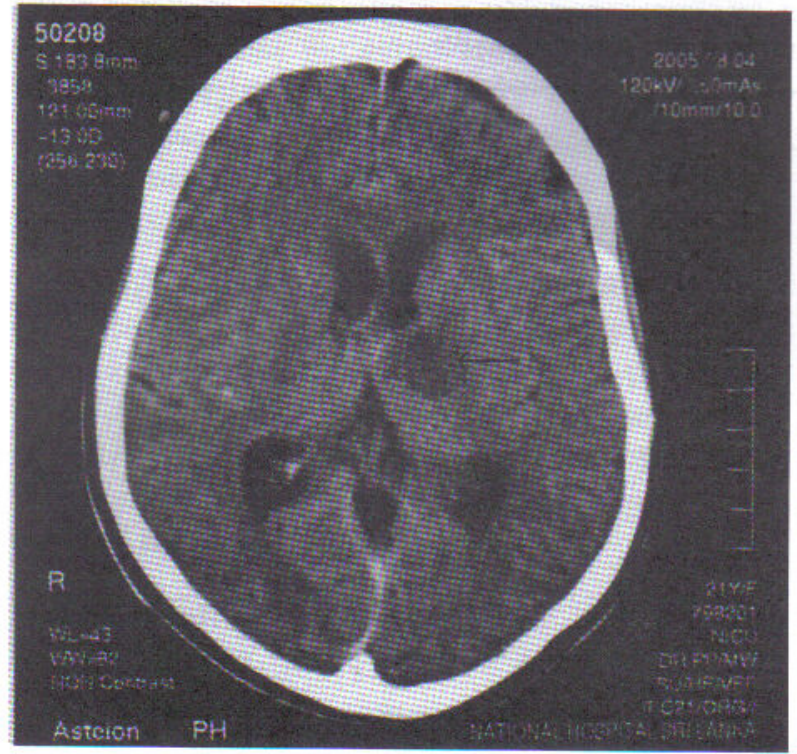

Figure 2. Computerized tomography of brain (patient 1) showing thalamic infarct (arrowed).

\section{Investigation of the outbreak}

A comprehensive epidemiological investigation was done by the Ministry of Health in conjunction with the national team of doctors appointed to investigate the outbreak and experts from the WHO [4]. Patients had

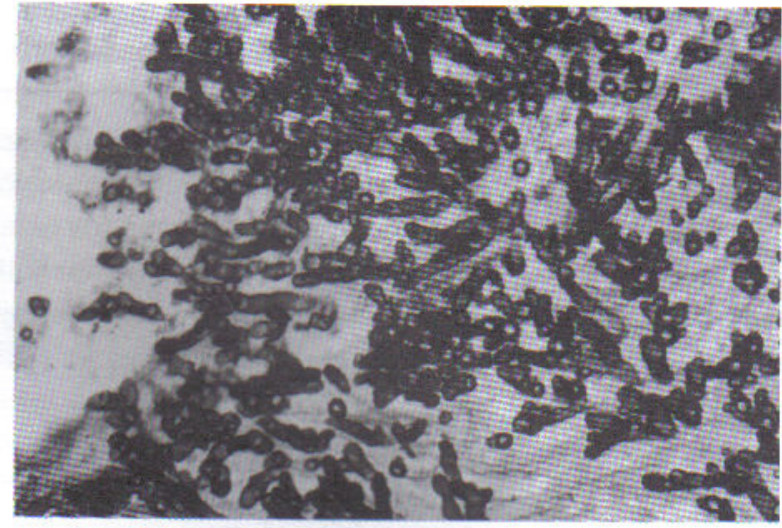

Figure 3. Histology of brain tissue with Grocott Gomori Silver stain showing fungal morphology.

undergone spinal anaesthesia in 2 hospitals within 4 weeks where the anaesthetists, obstetricians, nursing staff and theatre locations differed. Spinal anaesthesia had been carried out by trained medical officers under the supervision of a senior consultant anaesthetist, adhering to internationally approved guidelines for sterility using bupivacaine and fentanyl as the spinal anaesthetic agents.

The microbiology laboratories of the National Hospital and the Medical Research Institute tested, using standard laboratory procedures with internal quality control, a variety of relevant samples from the theatre staff

Table 2. Post-mortem findings

\begin{tabular}{|c|c|c|c|}
\hline Patients & 1 & 2 & 5 \\
\hline $\begin{array}{l}\text { Post-mortem } \\
\text { Fungal culture of brain }\end{array}$ & Aspergillus fumigatus & Aspergillus fumigatus & Aspergillus fumigatus \\
\hline $\begin{array}{l}\text { Post-mortem } \\
\text { macroscopy }\end{array}$ & $\begin{array}{l}\text { Cerebral oedema and SAH in the } \\
\text { base of brain cervical, thoracic, } \\
\text { lumbar and sacral regions seen. } \\
\text { Circle of Willis disturbed and } \\
\text { blood vessels not intact. } \\
\text { Cut surface brain - extensive } \\
\text { necrosis in parietal, temporal } \\
\text { and occipital areas with } \\
\text { haemorrhages in pons and } \\
\text { midbrain. }\end{array}$ & $\begin{array}{l}\text { Cerebral oedema and yellowish } \\
\text { exudates on surface of brain, } \\
\text { spinal cord and meninges seen. } \\
\text { Cut surface brain - erythematous } \\
\text { necrotic area involving both } \\
\text { lateral walls of anterior } \\
\text { horns of lateral ventricles } \\
\text { and ventriculitis. }\end{array}$ & $\begin{array}{l}\text { Cerebral oedema and SAH } \\
\text { in base of brain seen. } \\
\text { Circle of Willis congested } \\
\text { with perivascular haemorrage. } \\
\text { Spinal cord - distorted } \\
\text { with blood stained exudates } \\
\text { over surface in lumbar region. }\end{array}$ \\
\hline $\begin{array}{l}\text { Post-mortem } \\
\text { microscopy }\end{array}$ & $\begin{array}{l}\text { Extensive vasculitis with } \\
\text { lympho-plasmacytic infiltrate } \\
\text { and thrombosis. A focus with } \\
\text { granulomatous reaction with } \\
\text { fungal hyphae within. Grocott } \\
\text { Gomori silver stain for fungi } \\
\text { demonstrated septate hyphae } \\
\text { with branching compatible with } \\
\text { Aspergillus. }\end{array}$ & $\begin{array}{l}\text { Extensive vasculitis with necrosis } \\
\text { and haemorrhage in brain matter } \\
\text { together with angio-invasion by } \\
\text { Aspergillus fungi. }\end{array}$ & $\begin{array}{l}\text { Cerebral vessels show } \\
\text { angioinvasion by } \\
\text { Aspergillus fragments. } \\
\text { Haemorrhage and necrosis } \\
\text { in periventricular brain tissue. }\end{array}$ \\
\hline
\end{tabular}

$\mathrm{SAH}=$ subarachnoid haemorrhage 
and non-clinical samples from the theatres of the hospitals involved. These included randomly selected unopened 679 disposable plastic syringes, 159 intravenous and spinal needles, 87 cannulae, 13 gloves, 78 blood transfusion sets, 55 ampoules of anaesthetic agents and 213 samplings from the theatre environment. The crucial finding was that 43 syringes and two gloves were positive for Aspergillus fumigatus. They originated from three different manufacturers.

The central stores for drugs and devices of the Ministry of Health were examined since infection occurred in two different institutions. This revealed that the three regularly used renovated well maintained warehouses were full of tsunami donations, while the regular procurements of the Ministry were stored in a dusty and humid fourth warehouse with roof-leaks. The investigators concluded that sub-optimal storage for over 6 months after tsunami was the most plausible reason for this contamination (4).

\section{Measures implemented to control the outbreak}

When it was recognized that the infection was not confined to a single hospital, the Ministry of Health coordinated with consultant anaesthetists to control the outbreak by temporarily withholding spinal anaesthesia. Anaesthetists were provided with new stocks of spinal needles airlifted by WHO within a week. All syringes and needles distributed to hospitals during the suspected period were recalled, and were replaced with new stocks. All devices suspected to be contaminated were destroyed by incineration. A program of systematic recall of all women subjected to spinal anaesthesia during this period was also implemented.

\section{Discussion}

In a review of 59 reports of isolated cases of meningitis following spinal anaesthesia until 2000 [1], a bacterial pathogen was isolated in 52, with no cases of fungal meningitis. The mortality in this series was $5 \%$. Another study of 27 case reports of meningitis following spinal anaesthesia in India occurring over 18 years had a case fatality rate of $37 \%$ [2]. CSF cultures of those were positive in 6 for Pseudomonas aeruginosa, Staphylococcus aureus, Acinotobacter spp. and Mycobacterium tuberculosis. Five autopsies in the Indian series [2] revealed ruptured mycotic aneurysms of Aspergillus invasion of the basilar arterial tree. Our series is the first ever reported outbreak of iatrogenic fungal meningitis.

Sri Lanka with a population of 19 million has a government sponsored, free health care service with equitable access. The reported outbreak of meningitis occurred in Colombo where the population density is $3000 / \mathrm{km}^{2}$. The mean monthly caesarean section rate at the maternity hospital where the majority of cases occurred is about 800 . Spinal anaesthesia has been administered in this institution under the supervision of consultant anaesthetists for the previous decade, without any previous reports of iatrogenic meningitis.

An early ante-mortem diagnosis of the aetiological agent of the current outbreak was not possible. Long incubation period when compared with bacterial and chemical meningitis, bilateral lateral rectus palsy, papilloedema and lateralizing signs of stroke were atypical of bacterial and chemical meningitis. Bacterial cultures and PCR of CSF yielded little support of a specific causative organism. This is in keeping with other reports of Aspergillus meningitis. The Galactomannan test to confirm fungal antigen was not available locally [5]. Poor sensitivity and prolonged period needed for CSF fungal cultures, made it of little help for diagnosis and appropriate therapeutic decisions. The clinical course of illness suggested a virulent form of meningitis where a fungal cause was likely, and this was confirmed at autopsy. The undisputed autopsy isolation of Aspergillus fumigatus in 3 deaths confirms that this was indeed an outbreak of Aspergillus meningitis.

Aspergillus meningitis in immune competent individuals is exceedingly rare $[5,6]$, and could occur as a complication of direct inoculation during neurosurgery, spread from middle ear [5] or sinuses [6]. Central nervous system Aspergillosis has a spectrum of disease such as cerebrovascular aspergillosis, cerebral abscess, and mycotic cerebral aneurysms [7]. Aspergillus meningitis following inoculation at neurosurgery has an incubation period of 8 days to 1 year [7]. Characteristically, Aspergillus spp. tend to be invasive with a potential to induce vasculitis within major arteries at the base of brain that gives rise to vascular thrombosis and mycotic aneurysms, rather than abundant CSF evidence of Aspergillus. Clinical presentation of vascular involvement includes subarachnoid haemorrhage or stroke; both occurred in this case series.

Aggressive treatment with antifungal agents in those who survived was made possible by the autopsy report of the first patient. Although antifungal therapy was instituted on the two who died, time was inadequate for aggressive antifungal therapy in the light of the first autopsy report. The haematological, metabolic and neurological side-effects of antifungal agents encountered in the survivors, confirms the need to be cautious with empirical antifungal treatment in immune competent low risk individuals.

The inherent body immunity probably prevented developing the disease in most patients who received intramuscular and intravenous injections. Poorly developed immunity in the intrathecal space is likely to have caused the patients in the current series to develop the disease. All affected in the current series were pregnant 
women and none of the other gynaecological operations performed under spinal anaesthesia in the two hospitals by the same staff during the same period, developed iatrogenic meningitis. Neither were patients with iatrogenic meningitis referred from general surgical wards of NHSL. The reason for iatrogenic meningitis to occur only in postpartum women in the local series remains unresolved. A compromised immune state in pregnancy could have enhanced their susceptibility.

Sri Lanka faced its worst natural disaster in recorded history on 26 December 2004, with the tsunami taking more than 40000 lives and leaving 300000 displaced. There were no outbreaks of infectious diseases in tsunami victims, due to preventive measures taken by the health planners and providers. However, the disaster led to a massive influx of donations of drugs and medical devices that overwhelmed the regular checks in quality assurance and maintenance of records of issue to hospitals by the Ministry of Health. The capacity of storage facilities of the Ministry of Health were inadequate for storing the abundance of donations received during this period. Storage of disposable syringes with thin polythene outer covers, liable to easy damage under sub-optimal conditions, was considered as one of the most likely causes for this outbreak of meningitis.

We report 5 post-partum women with confirmed Aspergillus meningitis managed at NHSL. These cases were reported in a letter to editor in New England Journal of Medicine [9]. Few more with mild symptoms were screened for meningitis and were proved to be negative. This report stresses the difficulties encountered in the diagnosis and treatment of Aspergillus meningitis and related complications in a resource limited setting in a developing country, recovering from a human disaster of massive scale. The relative limitation in state of the art technology for microbiological confirmation was a serious problem.

We emphasize that the cause for this outbreak was not precisely identified. Detailed study from the manufacture of syringes to conditions of international transportation and storage are required. We report this outbreak as a warning of such a possibility being an effect of a lapse in quality assurance in a developing country faced with resource limitations following a natural disaster.

\section{Acknowledgements}

We thank Drs. N Abeyasingha and A Amarasingha of the Epidemiology Unit, Ministry of Health; Dr. Yvan F Hutin, WHO Resident Advisor, Indian Field Epidemiology Training Programme (FETP), Chennai, Tamil Nadu, India; Dr. RL Ichhpujani, Consultant Microbiologist, WHO office for the South East Asia region; and Arjun Srinivasan, MD, LCDR USPHS, Medical Epidemiologist, Division of Healthcare Quality Promotion, Centre for Disease Control and Prevention, Atlanta.

\section{References}

1. Yaniv LG, Potasman I. Iatrogenic meningitis: an increasing role for resistant viridans streptoccoci? Case report and review of the last 20 years. Scandinavian Journal of Infectious Disease 2000; 32: 693-7.

2. Pandian JD, Sarada C, Radhakrishnan VV, Kishore A. Iatrogenic meningitis after lumbar puncture - a preventable health hazard. Journal of Hospital Infection 2004; 56: 119-24.

3. Wong-Beringer A, Kriengkauykiat J. Systemic antifungal therapy: new options, new challenges. Pharmacotherapy 2003; 23: 1441-62.

4. Hutin YJF, Ichhpujani RL, in collaboration with Sri Lankan National Investigation team for the outbreak. Investigation report of the outbreak of health care associated meningitis in Sri Lanka, 2005. Accessed January 17, 2007, at http://www.searo.who.int/en/Section 10/ Section1973_10242.htm.)

5. Verweij E, Brinkman K, Kremer HPH, Kullberg B, Meis JFGM. Aspergillus meningitis: diagnosis by non-culturebased microbiological methods and management. Journal of Clinical Microbiology 1999; 37: 1186-9.

6. Stevens DA, Kan VL, Judson MA, Morrison VA, Dummer $\mathrm{S}$, et al. Practice guidelines for diseases caused by Aspergillus. Clinical Infectious Diseases 2000; 30: 696709.

7. Hope WW, Walfh JJ, Denning DW. The invasive and saprophytic syndrome due to Aspergillus species. Medical mycology - dvances against Aspergillosis. Proceedings of the Advances Against Aspergillosis Conference. 2005; 43 : S207-38

8. Ganapathi M. Imported syringes triggered meningitis in Sri Lanka. British Medical Journal 2005; 331: 535.

9. Gunaratne PS, Wijeyaratne CN, Seneviratne HR. Aspergillus meningitis in Sri Lanka, a post-tsunami effect? New England Journal of Medicine 2007; 356 : 754-6. 